\title{
Radial artery pseudoaneurysm (RAP) following transradial intervention - an extremely rare complication successfully managed by surgery: case report
}

\author{
Santosh Kumar Sinha, Mukesh Jitendra Jha, Vikas Mishra, Mahmadula Razi, Anupam Mahrotra, \\ Mohammad Asif, Nasar Abdali, Vikas Chaturvedi, Lokendra Rekwal \\ Department of Cardiology, L.P.S Institute of Cardiology, G.S.V.M Med. College, Kanpur, India
}

\begin{abstract}
The transradial access for diagnostic and therapeutic purpose is becoming increasingly popular, mainly because of its lack of complications. Radial artery pseudoaneurysm (RAP) is an extremely rare complication, so many of its clinical features are unknown and treatment is not systematic. Therapeutic options are conservative management, ultrasound-guided compression, thrombin injection and surgical intervention. Here, we report a 43-year old female who underwent transradial percutaneous angioplasty of left anterior descending artery. During cannulation of her radial artery, multiple puncture attempts were done. Upon removal of the transradial compression band (TR Band), forearm ecchymosis and small hematoma were noted with mild pain. Tight compression bandage was applied but on the following day, she had complaints of increasing right forearm pain and tenderness. Physical evaluation revealed increased swelling of the right forearm and an ultrasound of the right forearm demonstrated a RAP of the right radial artery measuring up to $3.9 \times 1.9 \mathrm{~cm}$ with $3.4 \mathrm{~mm}$ neck. Tight compression bandage was further prolonged following ultrasound compression with vascular probe which failed to alleviate her complaints. Following failure of conservative therapy and in lieu of her symptoms, surgical exploration, clot removal and successful repair was done.
\end{abstract}

Key words: radial artery pseudoaneurysm, surgery, transradial intervention, thrombin injection, ultrasound compression

Acta Angiol 2017; 23, 4: 165-169

\section{Introduction}

The transradial access for diagnostic and therapeutic purpose is becoming increasingly popular, mainly because of its lack of complications [I]. Radial artery pseudoaneurysm (RAP) is an extremely rare complication of transradial intervention [2]. The other causes are trauma, vascular access for arteriovenous fistulae for dialysis $[3,4]$ and peripheral arterial cannulation for continuous blood pressure monitoring and arterial blood gas analysis [5]. The main risk factors are age, sepsis, diabetes mellitus, patients on haemodialysis, duration of catheterisations, multiple attempts, hypertension, use of anticoagulants and improper compression following removal of transradial compression band (TR band) and the occurrence of hematoma in the forearm during/ /after compression among patients on anticoagulants and antiplatelets [6, 7]. Although nonsurgical modalities of treatment have emerged in recent years, surgery still remains the gold standard.

Address for correspondence: Santosh Kumar Sinha, Department of Cardiology, L.P.S Institute of Cardiology, G.S.V.M Med. College, Kanpur, India, e-mail: fionasan@rediffmail.com 


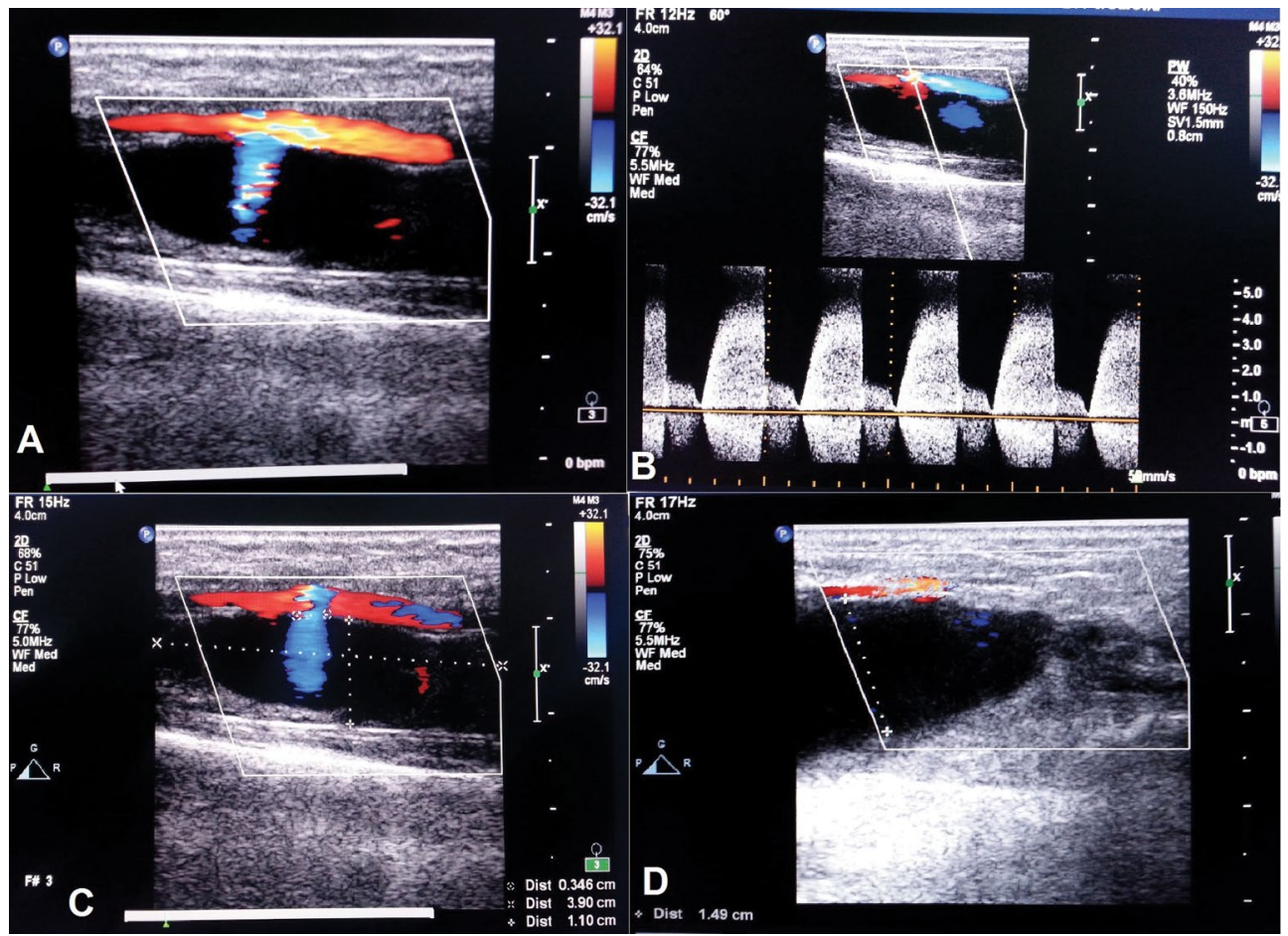

Figure I. Radial artery pseudoaneurysm after transradial catheterization by vascular Doppler study (A, B, C on Day I; D — on Day 2)

\section{Case study}

A 43-year-old female underwent coronary angiography for chronic stable angina despite guideline directed medical therapy with strongly positive tread mill test. Her past medical history was otherwise significant except for hypertension and dyslipidemia. Electrocardiogram suggested mild ST-T changes and normal sinus rhythm. Echocardiogram revealed mild concentric left ventricular hypertrophy, Grade I diastolic dysfunction and normal systolic function with ejection fraction of $60 \%$. Coronary angiography was performed via right radial artery access after an informed consent. The Allen's test was performed prior to the catheterization. Radial artery was punctured by 2 I G needle after multiple hits and $0.02 \mathrm{I}$ " guide wires (Avanti transradial kit; Cordis Corp, USA) was inserted. 6F sheath was placed and cocktail containing $200 \mu \mathrm{g}$ nitroglycerin, $2.5 \mathrm{mg}$ diltiazem, and $2500 \mathrm{IU}$ unfractioned heparin were injected was administered. Coronary angiogram revealed discrete eccentric lesion with near total occlusion of proximal left anterior descending artery. She was further loaded with dual antiplatelet therapy in the cath lab (aspirin $325 \mathrm{mg}$ and prasugrel $60 \mathrm{mg}$ ) and the procedure was performed using heparin (6000 units) for anticoagulation. Lesion was successfully stented by
Xience Prime drug eluting stent (Abott, USA) at 12 ATM pressure achieving TIMI III flow with an activated clotting time (ACT) of 292 second at the end of procedure. Radial sheath was removed just after the procedure and compression was performed for $2 \mathrm{~h}$ with a radial compression device (TR band; Terumo, Inc) using the "patent haemostasis" protocol. She complained of mild pain and a small haematoma was noted in mid forearm upon removal of TR band. A tight pressure bandage (dynaplast) was applied and she was shifted to coronary care unit which was removed next day. However, she complained of increasing right forearm pain and tenderness. Local examination revealed increased swelling of the right forearm, hematoma and ecchymosis at the right wrist proximal to the access site. An ultrasound of the right wrist demonstrated a pseudoaneurysm of the radial artery measuring up to $1.1 \mathrm{~cm}$ in diameter with a $3.4 \mathrm{~mm}$ neck (Fig. IA, B, C). The neck of RPA was compressed by using vascular probe for $30 \mathrm{~min}$ with little relief in her symptoms. A 2-inch elastic wrap (dynaplast) was used from the forearm to the wrist to proximal forearm, maintaining sufficient tension during wrapping. Pulse oximetry tracings of all five digits were reviewed after application, which confirmed preserved perfusion. She was administered analgesics. On the next day, her pain had increased with tenderness. On 


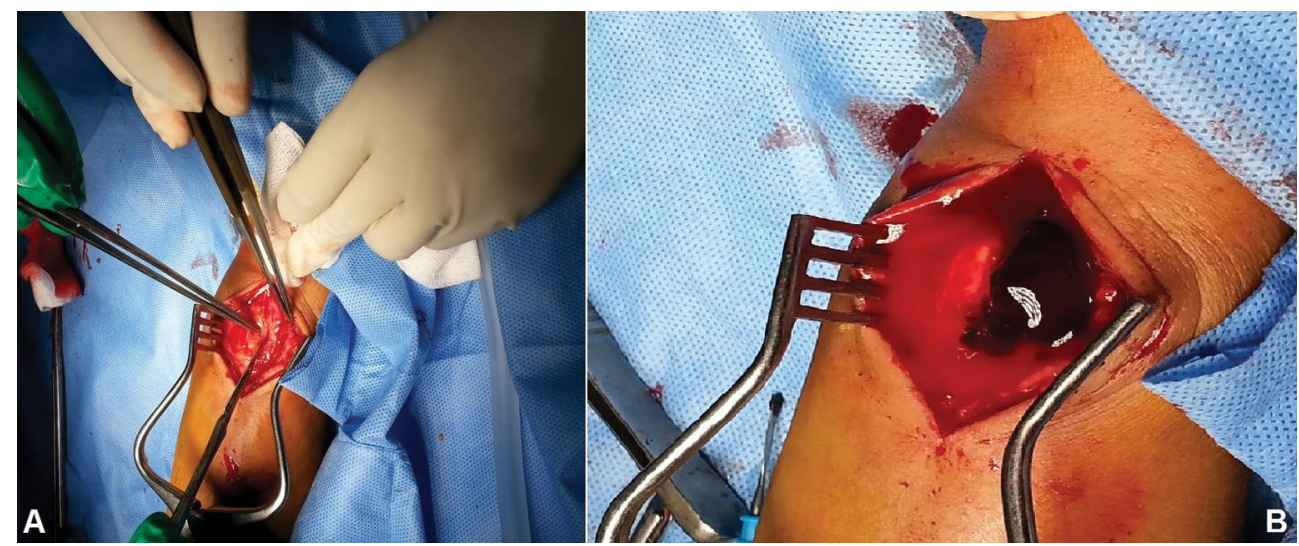

Figure 2. Surgical exploration of pseudoaneurysm (A, B - clot visible in the sac)

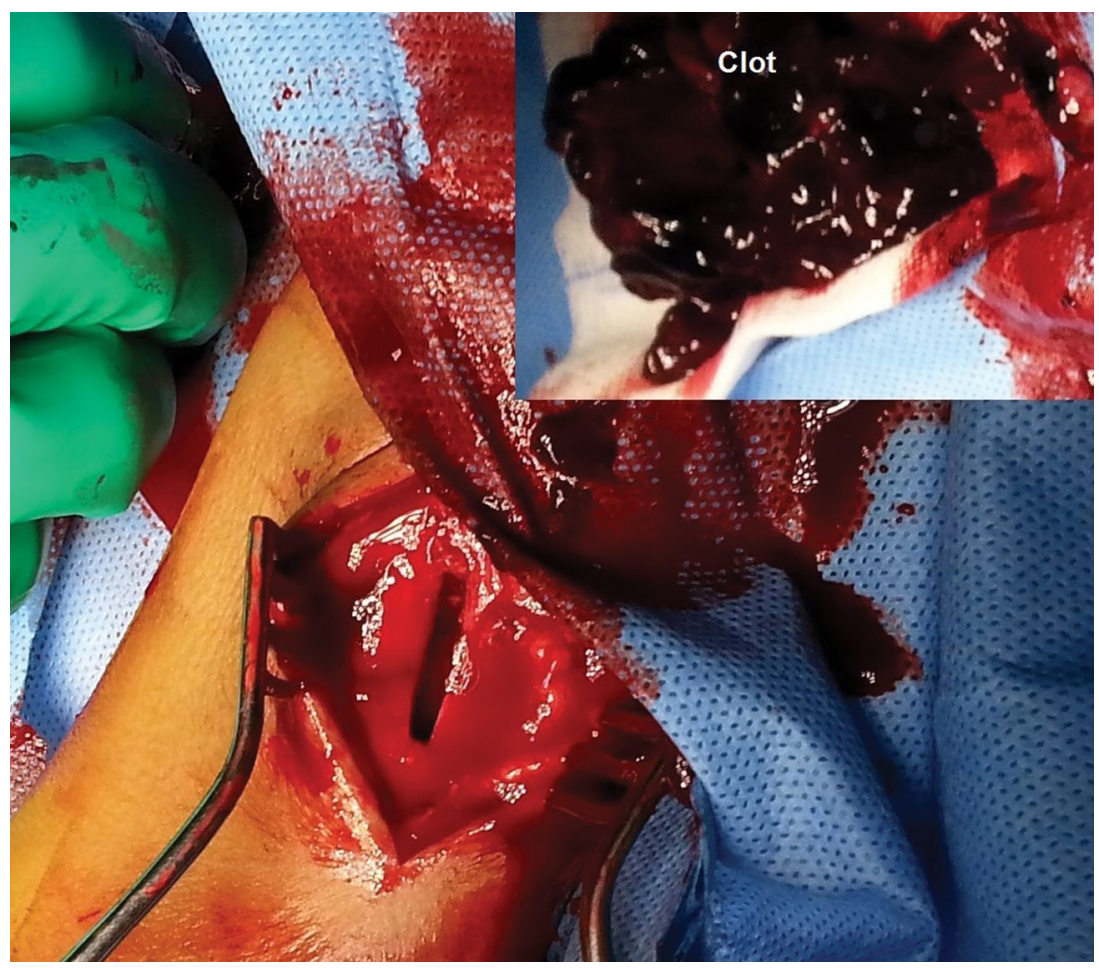

Figure 3. Evacuation and extraction of clot

repeat doppler examination, sac was bigger in depth (Fig. ID). Sensation was normal except for decreased sensation over a small area of the medial right thumb. In lieu of her complaints, surgical opinion was sought and surgical exploration was decided. Skin at local site was infiltrated with $2 \%$ xylocaine. After exploration, sac of RPA was incised and blood clots were removed (Fig. 2A, B, Fig. 3). Rent in radial artery was identified (Fig. 4) and successfully repaired. The patient had sig- nificant improvement in her symptoms with complete resolution of ecchymosis over couple of weeks. Serial subsequent ultrasounds confirmed successful treatment of PSA with preserved radial artery flow.

\section{Discussion}

Transradial catheterization has significantly reduced the incidence of access site complications [8]. However, 


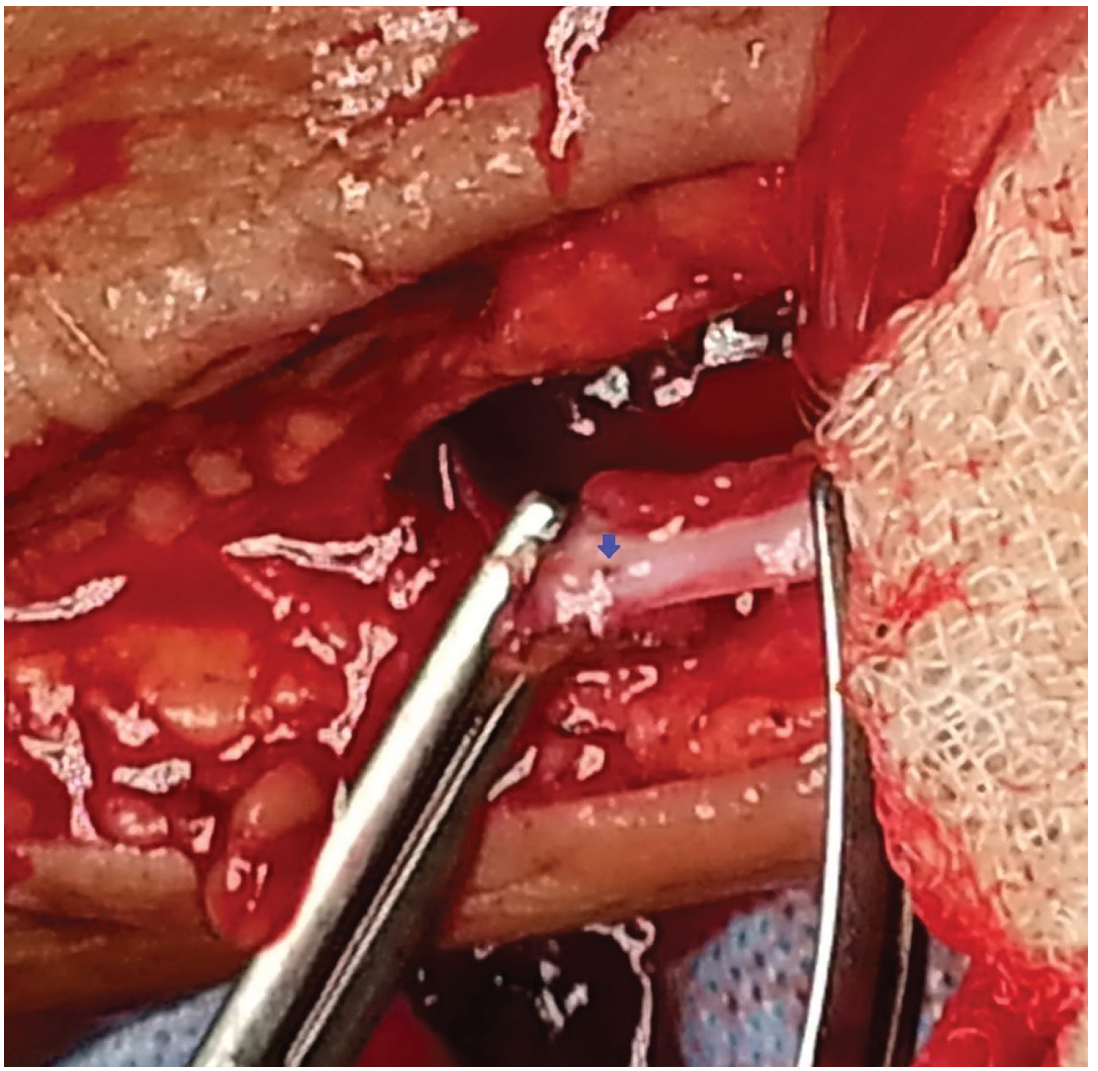

Figure 4. Visible tear on the posterior wall of the radial artery (blue arrow showing the rent)

complications of Transradial access do occur, including radial artery occlusion, non-occlusive injury, spasm, hand ischemia, nerve damage, bleeding, and rarely pseudoaneurysm (RPA) formation [2, 9]. RPA occurs as it is a tear through all the layers of the artery with concomitant haemorrhage resulting into a hematoma, being contained by the surrounding tissue creating a false sac [3]. Incidence of RPA with TR access is $<0.1 \%$ as reported by Collins et al. [10] in their case series. Multiple puncture attempts, ongoing systemic anticoagulation, inadequate haemostasis, vascular site infection, arterial calcification, the use of larger sheaths are some of factors that predispose the development of PSA [II]. Treatment of RPA is based on the anatomic characteristics of the PSA with various options being conservative treatment, prolonged haemostatic compression, ultrasound compression, local thrombin injection and surgical exploration with repair. RAP is very fragile. The layer of tissue separating them from the exterior is extremely thin and can undergo iatrogenic rupture because of direct mechanical pressure. However, the low incidence rate and limited literature on various haemostatic devices provide insufficient data to enable an assessment of the efficacy of various haemostatic devices to prevent radial artery PSA. Moreover, potential problems originating from these devices include incorrect positioning and inadequate pressure for compression at the access site [12].

Direct mechanical compression using ultrasound vascular probe is another option but it can lead to iatrogenic rupture of the outer wall as reported by Isabel et al. [7]. Thrombin injection would have been another option but the potential problem is acute occlusion of the radial artery as reported by lsabel et al. [7]. Also, it should be ventured for RPA with smaller neck. In our case, as the neck was large and conservative treatment failed, we went for surgical exploration and repair. As haematoma was large, other treatment options would have been futile. If the patient develop radial artery RAP, conservative treatment should be exercised initially using compression with a pneumatic device which should be applied against the radial artery proximally to the RAP and not directly against the RAP as it was done in our case. This proximal compression must be occlusive. Because of the possibility that blood may enter the RAP through the palmer arch via the ulnar 
artery, the absence of flow in the RAP must be verified by vascular ultrasound, or if not possible, by palpation (absence of pulsatility). Therefore, surgical intervention is the gold standard modality when other options fail.

\section{Conflict of interest}

None.

\section{References}

I. Rodríguez-Olivares R, García-Touchard A, Fernández-Díaz J, et al. Abordaje transulnar con arteria radial homolateral ocluida: descripción de la vascularización del antebrazo y seguimiento a largo plazo. Revista Española de Cardiología. 2014; 67(10): 854-855, doi: 10.1016/j.recesp.2014.05.016.

2. Sanmartín M, Cuevas D, Goicolea J, et al. Complicaciones vasculares asociadas al acceso transradial para el cateterismo cardíaco. Revista Española de Cardiología. 2004; 57(6): 58I-584, doi: 10.1016/s0300-8932(04)77150-x.

3. Kerr CD, Duffey TP. Traumatic false aneurysm of the radial artery. J Trauma. 1988; 28(I I): 1603-1604, doi: 10.1097/00005373198811000-00018, indexed in Pubmed: 3184228.

4. Komorowska-Timek E, Teruya TH, Abou-Zamzam AM, et al. Treatment of radial and ulnar artery pseudoaneurysms using percutaneous thrombin injection. J Hand Surg Am. 2004; 29(5): 936-942, doi: 10.1016/j.jhsa.2004.05.009, indexed in Pubmed: 15465248.

5. Swanson E, Freiberg A, Salter DR. Radial artery infections and aneurysms after catheterization. J Hand Surg Am. 1990; I5(I):
|66-|7|, doi: |0.10|6/s0363-5023(09)9||26-1, indexed in Pubmed: 2299159.

6. Ganchi PA, Wilhelmi BJ, Fujita K, et al. Ruptured pseudoaneurysm complicating an infected radial artery catheter: case report and review of the literature. Ann Plast Surg. 200 I; 46(6): 647-650, doi: 10.1097/00000637-200106000-00015, indexed in Pubmed: I 1405368.

7. Isabel Zegrí, Arturo García-Touchard, Sofía Cuenca, Juan Francisco Oteo, José Antonio Fernańdez-Díaz, and Javier Goicolea. Radial Artery Pseudoaneurysm Following Cardiac Catheterization: Clinical Features and Nonsurgical Treatment Results. Scientific letters/Rev Esp Cardiol. 2015; 68(4): 343-354.

8. Kiemeneij F, Laarman GJ, Odekerken D, et al. A randomized comparison of percutaneous transluminal coronary angioplasty by the radial, brachial and femoral approaches: the access study. J Am Coll Cardiol. 1997; 29(6): 1269-1275, doi: 10.1016/s07351097(97)00064-8, indexed in Pubmed: 9137223.

9. Kanei Y, Kwan T, Nakra NC, et al. Transradial cardiac catheterization: a review of access site c06,392mplications. Catheter Cardiovasc Interv. 201 I; 78(6): 840-846, doi: 10.1002/ ccd.22978, indexed in Pubmed: 21567879.

10. Collins N, Wainstein R, Ward M, et al. Pseudoaneurysm after transradial cardiac catheterization: case series and review of the literature. Catheter Cardiovasc Interv. 2012; 80(2): 283-287, doi: 10.1002/ccd.23216, indexed in Pubmed: 21735525.

II. Liou M, Tung F, Kanei Y, et al. Treatment of radial artery pseudoaneurysm using a novel compression device. J Invasive Cardiol. 2010; 22(6): 293-295, indexed in Pubmed: 205I65II.

12. Hamid T, Harper L, McDonald J. Radial artery pseudoaneurysm following coronary angiography in two octogenarians. Exp Clin Cardiol. 2012; 17(4): 260-262, indexed in Pubmed: 23592950. 
